\title{
Liposarcoma of the Back: Case Report
}

\author{
A. Maïga1 ${ }^{*}$, I. Diakité1, A. Bah1, T. Bathio², B. Diassana², A. B. Diallo², A. A. Traoré1, M. Diallo3, \\ B. T. Dembélé1, Y. Sidibé1, O. H. Saadé1, M. Kanté ${ }^{2}$, M. Konaté1, S. Dembélé1, M. Samaké1, \\ A. Togo' ${ }^{1}$, A. Traoré1, G. Diallo' ${ }^{1}$
}

\author{
${ }^{1}$ Service of General Surgery, Teaching Hospital Gabriel Touré, Bamako, Mali \\ ${ }^{2}$ Service of General Surgery, Hospital of Sikasso, Sikasso, Mali \\ ${ }^{3}$ Reference Heath Center of Commune VI, Bamako, Mali \\ Email: *amadoumaiga3@gmail.com
}

How to cite this paper: Maïga, A., Diakité, I., Bah, A., Bathio, T., Diassana, B., Diallo, A.B., Traoré, A.A., Diallo, M., Dembélé, B.T., Sidibé, Y., Saadé, O.H., Kanté, M., Konaté, M., Dembélé, S., Samaké, M., Togo, A., Traoré, A. and Diallo, G. (2019) Liposarcoma of the Back: Case Report. Surgical Science, 10, 141-145.

https://doi.org/10.4236/ss.2019.104017

Received: March 6, 2019

Accepted: April 27, 2019

Published: April 30, 2019

Copyright (C) 2019 by author(s) and Scientific Research Publishing Inc. This work is licensed under the Creative Commons Attribution International License (CC BY 4.0).

http://creativecommons.org/licenses/by/4.0/

\begin{abstract}
Liposarcoma is a particular form of soft tissue sarcoma. First described by Virchow in 1860, liposarcoma is a rare mesenchymal tumor [1]. It represents $14 \%$ to $18 \%$ of all malignant tumors of the soft tissues and constitutes the most frequent soft tissue sarcoma [2]. For the majority of authors, it affects adult after the fourth decade. Because of the unusual age, we report a case of largeliposarcoma of the dorsal surface of the trunk. The appearance of the operative part made us think of a possible malignancy. A 35-year-old man without a notable patient history was admitted for a mass of the back discovered three years before without any notion of trauma. The patient affirms the recent appearance of an induration motivating the consultation. There were no associated signs such rectorrhagia, hematemesis, emaciation, pain. The physical examination finds a patient in good general condition. Locally, there is a swelling of the right lateral part of the $1 / 3$ middle part of the back. It is an oval swelling of $25 \mathrm{~cm}$ long axis. Any fat tumor having a size more than $5 \mathrm{~cm}$ must therefore receive special attention even before the fourth decade.
\end{abstract}

\section{Keywords}

Liposarcoma, Unusualage, Malignancy

\section{Introduction}

Liposarcomas are generally rare and their incidence does not exceed 2.5 cases/million inhabitants/year [1]. This rarity is relative because liposarcomas still represent $14 \%$ to $18 \%$ of all malignant tumors of the soft tissues [2]. They are the most common soft tissue sarcomas [3]. They predominate at the level of the limbs (50\%) but can also develop at the level of the trunk (33\%) [2]. Because of the unusual age, we report a case of large liposarcoma of the dorsal surface of the 
trunk in a 35-year old patient.

\section{Patient and Observation}

A 35-year-old man without a notable patient history was admitted for a mass of the back discovered three years before without any notion of trauma. The patient affirms the recent appearance of an induration motivating the consultation. There were no associated signs such rectorrhagia, hematemesis, emaciation, pain.

The physical examination finds a patient in good general condition. Locally, there is a swelling of the right lateral part of the $1 / 3$ middle part of the back. It is an oval swelling of $25 \mathrm{~cm}$ long axis (Figure 1, Figure 2). The surrounding skin looks normal. At palpation the swelling is firm, poorly limited and mobile compared to superficial and deep planes and not painful. The axillary and cervical ganglion areas are free of any adenopathies. The rest of the somatic examination was normal. The chest CT scan (Figure 3) shows images in favor of a fat mass of the right chest wall of benign shape. The patient underwent tumor excision under general anesthesia. The incision was linear compared to the mass. After opening the fascia and dissecting the fibers of the large dorsal muscle, the tumor was exposed presenting as a fatty mass. Excision of the entire tumor and its capsule is performed (Figure 4). The continuations were simple with no tumor recurrence to date (18 months).

The pathological examination of the operative specimen shows a globally lobulated tumor proliferation. The lobules are surrounded by fibrous septa of variable thickness. Within the intra-lobular mature adipocyte plaques, there is the presence of numerous lipoblasts and atypical adipose cells with multi-vacuolar cytoplasm with a nucleolarhyperchromatic nucleus and notch-like appearance. No tumor necrosis was noted and this proliferation is surrounded by a thin fibrous capsule. The diagnosis of well differentiated liposarcoma of sclerosing type was made. The patient was introduced to the multidisciplinary oncology staff.

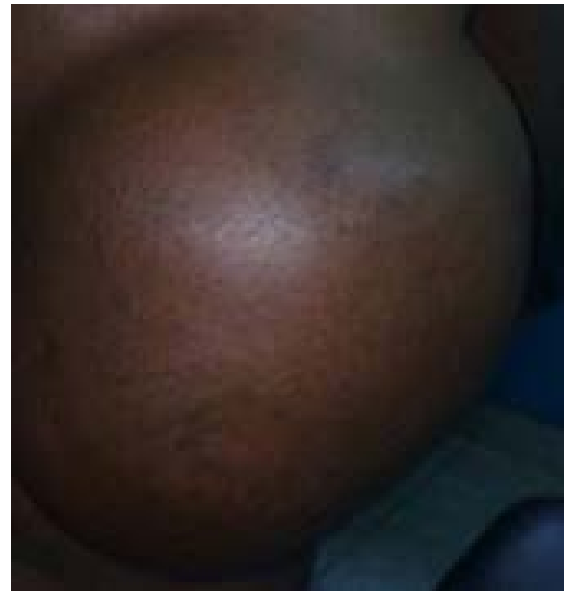

Figure 1. Mass of the middle $1 / 3$ of the back (dorsal view). 


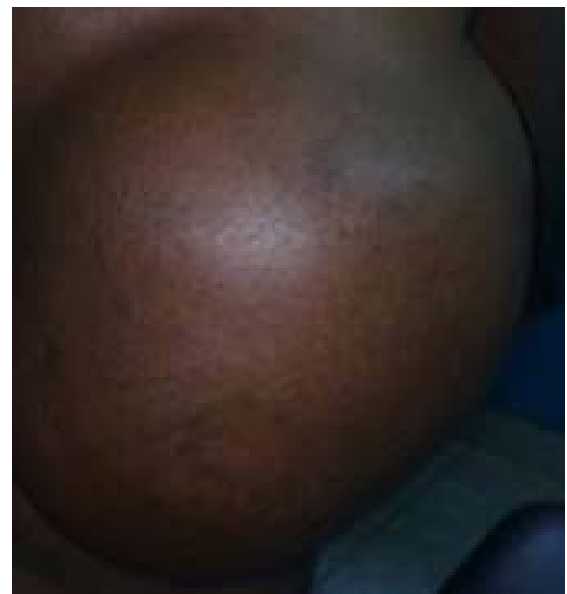

Figure 2. Mass of the middle $1 / 3$ of the back (side view).

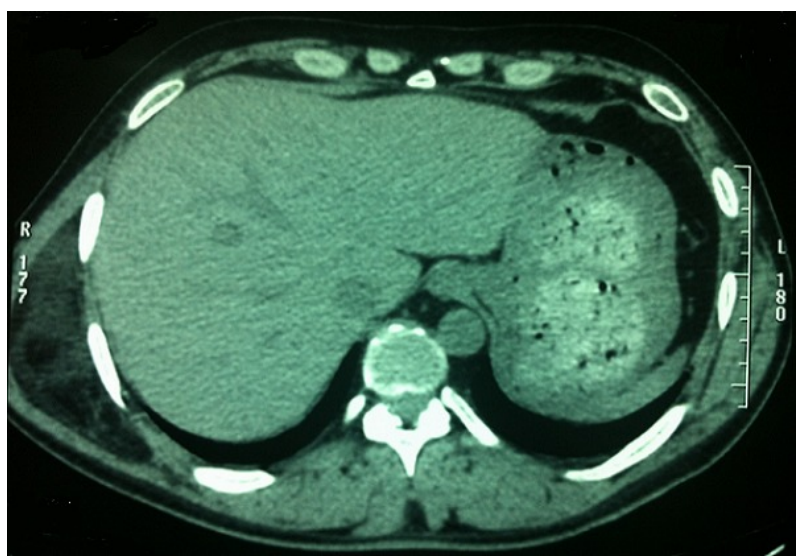

Figure 3. Tumor mass of the middle $1 / 3$ of the back (cross section).

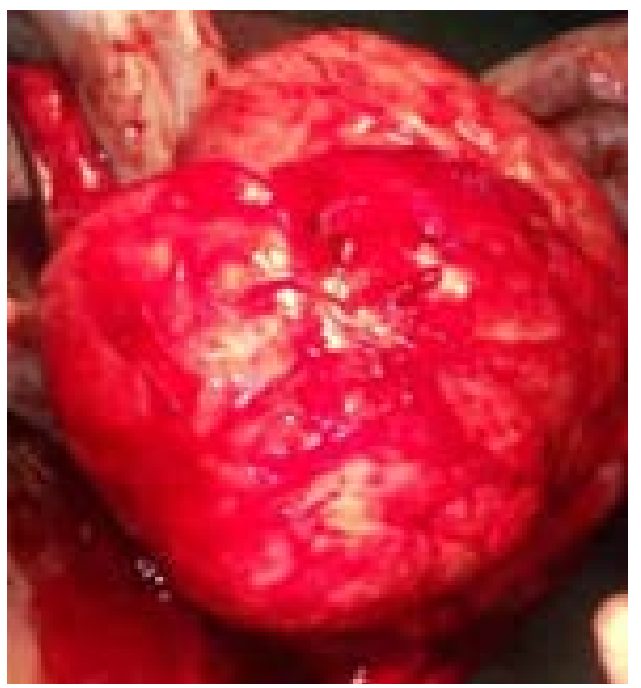

Figure 4. Total excision of the tumor and its capsule.

\section{Discussion}

First described by Virchow in 1860, liposarcoma is a rare mesenchymal tumor 
[1]. However, it is the most common soft tissue sarcoma [3] [4]. It most often affects the adult subject. Some authors find it between 50 and 70 years [2] [5], others delimits a period of 40 to 60 years [3], therefore affects the adult after the fourth decade with a male predominance. In our case it's a young adult of 35 years, what makes the peculiarity. According to some authors, liposarcoma develops at the expense of primitive mesenchymal cells rather than at the expense of adipocytes. It would never develop on a lipoma or pre-existing lipomatosis [3] [5]. Indeed genetic or traumatic factors could promote this differentiation of adipocytes [6]. Clinically, liposarcoma is in the form of a bulky mass generally greater than $5 \mathrm{~cm}$ in size. For this purpose several authors report a parallelism between the size of the fat tumors and their malignancy with up to $74 \%$ sensitivity of malignancy if the size is greater than $5 \mathrm{~cm} \mathrm{[7]} \mathrm{[8].} \mathrm{This} \mathrm{tumoral} \mathrm{mass} \mathrm{is} \mathrm{of}$ variable aspect, most often nodular well limited [1] [3]. The deterioration of the general state and the pains are rare and are found only at the end of evolution [2]. Any fat tumor having a size more than $5 \mathrm{~cm}$ must therefore receive special attention even before the fourth decade. Pathologically, there are five types of liposarcoma; well differentiated, myxoid, round cell, pleomorphic, dedifferentiated. Liposarcomas of themyxoid type and of well-differentiated type are the most frequent. [3] [6] [9] [10]. The well-differentiated liposarcomas are tumors of low grade malignancy looking like lipomas hence the name "lipoma like" [2] with the presence of some lipoblasts [3] as shown by the pathological examination of our operative specimen. Whatever histological type, surgical excision is the key to treatment. It may, in some cases be supplemented by radiotherapy and sometimes chemotherapy especially in multiple metastases or inoperable cases. The prognosis of liposarcoma generally depends on the histological type, the size of the tumor and its extent at the time of diagnosis [2]. In all cases, recurrences are frequent and usually occur within 24 months after surgical treatment. Metastases are possible; the most common are pulmonary and hepatic and are haematogenous. However, liposarcoma of well-differentiated type is of better prognosis with a survival rate of more than $50 \%$ at 10 years [2] [3]. In addition, adequate initial surgical management combined when indicated with a wellmanaged adjuvant treatment can reduce recurrences.

\section{Conclusion}

Any fat tumor having a size more than $5 \mathrm{~cm}$ must therefore receive special attention even before the fourth decade.

\section{The Consent}

We received the patient's consent.

\section{Conflicts of Interest}

The authors declare no conflicts of interest regarding the publication of this paper. 


\section{References}

[1] Rahal, M., Said, B., et al. (2006) Liposarcome Cervico-Mediastinal. Feuillet de Radiologie, 46, 349-353. https://doi.org/10.1016/S0181-9801(06)70534-6

[2] Alain, F., Philippe, H., et al. (2002) Tumeurs graisseuses des parties molles des membres et des ceintures de l'adulte. Journal of Radiology, 83, 1035-1057.

[3] Thierry, D., Simon, E., et al. (2006) Pathologies hypertrophiques des tissus graisseux de la face. Revue de Stomatologie et de Chirurgie Maxillo-Faciale, 107, 354-360. https://doi.org/10.1016/S0035-1768(06)77063-2

[4] Kilpatrick, S.E., Doyon, J., Choong, P.F., Sim, F.H. and Nascimento, A.G. (1996) The Clinic Pathologic Spectrum of Mixoide and Round Cell Liposarcoma: A Study of 95 Cases. Cancer, 77, 1450-1458. https://doi.org/10.1002/(SICI)1097-0142(19960415)77:8<1450::AID-CNCR5>3.0.C $\underline{\mathrm{O} ; 2-\mathrm{G}}$

[5] Hiroto, I., Yochikau, F., Usuda, R., Ohta, S., Nakajima, N. and Muro, H. (2004) Liposarcoma Originating in the Neck and the Mediastinum after Removal of Mediastinallipoma. Kyobu Geka, 57, 935-940.

[6] Skubitz, K.M., Cheng, E.Y., Clohisy, D.R. and Thompson, R.C. (2005) Differential Gene Expression in Liposarcoma, Lipoma and Adipose Tissue. Cancer Investigation, 23, 105-118. https://doi.org/10.1081/CNV-50432

[7] De Schepper, A.M., De Beuckelleer, L., Vandervenne, J. and Somville, J. (2000) Magnetic Resonance Imaging of Soft Tissue Tumors. European Radiology, 10, 213-222. https://doi.org/10.1007/s003300050037

[8] Rydholm, H. and Berg, N.O. (1983) Size and Clinical Incidence of Lipoma and Sarcoma. Acta Orthopaedica Scandinavica, 54, 929-934.

https://doi.org/10.3109/17453678308992936

[9] Zhong, L.P., Zhao, S.F., Chen, G.F. and Ping, F.Y. (2004) Ultrasonographic Appearance of Lipoma in the Oral and Maxillofacial Region. Oral Surgery, Oral Medicine, Oral Pathology, Oral Radiology, and Endodontology, 98, 738-740. https://doi.org/10.1016/j.tripleo.2004.04.022

[10] Latter, R. (1981) Armed Forces Institute of Pathology. Vol. 1, Tumors of Soft Tissues, Atlas of Tumor Pathology Second Series, Washington DC, 53-150. 